Published by Al-Nahrain College of Medicine P-ISSN 1681-6579

E-ISSN 2224-4719

Email: iraqijms@colmed-alnahrain.edu.iq http://www.colmed-alnahrain.edu.iq http://www.iraqijms.net

\title{
The Role of Atorvastatin in the Treatment of Chronic Obstructive Pulmonary Disease with Elevated High Sensitive C-Reactive Protein
}

\author{
Ali S. Baay MRCP, FIBMS (Medicine), FIBMS (Respiratory) \\ Dept. of Internal Medicine, College of Medicine, Babylon University, Iraq
}

Abstract
Background

Objective

Methods

Results

Conclusion

Keywords

DOI: 10.22578/IJMS.14.4.12

List of abbreviation: HMG-COA = 3-hydroxy-3-methyl-glutarylcoenzyme $\mathrm{A}, \mathrm{COPD}=$ Chronic obstructive pulmonary disease, $\mathrm{FEV} 1$ = Forced expiratory volume in 1 second, CRP = C-reactive protein, HsCRP $=$ High sensitivity C-reactive protein,

\section{Introduction}

$\mathrm{O}$ ver the last 20 years, there has been a growing interest in the potential beneficial effects of 3-hydroxy-3methyl-glutaryl-coenzyme A (HMG-CoA) reductase inhibitors (statins) in chronic obstructive pulmonary disease (COPD) ${ }^{(1-5)}$. progression or reduce mortality. markers.
There is a growing interest in the potential beneficial effects of 3-hydroxy-3-methyl-glutarylcoenzyme A (HMG-CoA) reductase inhibitors drugs (statins) in chronic obstructive pulmonary disease (COPD) as anti-inflammatory agent. The basis of the systemic inflammation in COPD comes from two possibilities: spill-over effect or inherent systemic-based pro-inflammatory state conferred by a genetic disposition. The inhaler-based therapy for COPD aims to reduce symptoms,

To assess the efficacy and safety of statin therapy in COPD patients with evidence of inflammatory

Ninety patients were included in the study, aged 40 years or more, who visit the outpatient private clinic in Babylon government, Iraq from September 2012 to April 2016. They were divided randomly for 3 groups (receiving $40 \mathrm{mg}, 10 \mathrm{mg}$ atorvastatin or placebo, respectively), in addition to their baseline treatment. Severity reassessment performed after 6 months' duration of treatment as well as hospitalization frequency and mortality.

Statin therapy showed a significant improvement in the both doses treated groups regarding the HsCRP, CAT (chronic obstructive airway disease assessment test) score and forced expiratory volume in first second after 6 months of treatment. This improvement fails to be reported significant effect on CAT score when compared to placebo group. Thus, statin treatment doesn't improvement of hospitalization, number of exacerbations but not mortality.

Atorvastatin, statins, COPD, high sensitive C-reactive protein.

The clinical studies suggest that statin therapy may confer a number of benefits in COPD such as reducing both the frequency of, and mortality from, infective exacerbations, reducing mortality from pneumonia, reduced decline in lung function and reduced risk of lung cancer ${ }^{(1,2,4)}$. While the benefits of statin therapy in COPD can be rationally explained by the known pharmacological effects of statins on the lungs ${ }^{(5,6)}$ and justified where co-morbid cardiac disease commonly exists ${ }^{(1,7)}$. 
The basis of the systemic inflammation in COPD comes from two possibilities; either 'spill-over' effect from inflammation driven primarily in the lungs in response to aero-pollutants chiefly cigarette smoke exposure, neutrophilic inflammation and recurrent infection ${ }^{(8)}$ or inherent systemic-based pro-inflammatory state conferred by a genetic disposition ${ }^{(1,9)}$. Smoking significantly enhances (possibly unmasking) this inflammatory disposition by being a recurring pro-inflammatory stimulus to the pulmonary and immune systems. This possibility is supported by data showing that poor lung function (reduced forced expiratory volume in 1 second (FEV1)), independent of smoking, predicts poor vascular and respiratory outcomes ${ }^{(10,11)}$. Conversely normal lung function, even after decades of smoking exposure, confers a greater 'degree of protection' from cardiorespiratory outcomes than that observed in those with poor lung function who have been lifelong non-smokers. These observations raise the possibility that systemic inflammation could be a secondary driver of inflammation in the bronchial epithelium alongside that derived from smoke exposure ('reverse' effect) ${ }^{(11,12)}$.

Given that statins have been shown to lower systemic inflammation through inhibition of the inflammatory pathways mediated by NF-KB and IL-6 ${ }^{(13)}$. It is no surprise that statins are now considered effective anti-inflammatory agents, lowering systemic markers (IL-6 and Creactive protein (CRP)) by over $50 \%$ in a matter of days ${ }^{(13,14)}$. It should not be forgotten that statins also possess important anti-apoptotic, anti-oxidant and anti-proliferative effects, whether these are independent of their antiinflammatory effects is not known ${ }^{(14)}$.

In the treatment of COPD, while currently recommended therapy for COPD is primarily inhaler-based, where the aim is to reduce symptoms, improve quality of life and reduce hospitalization, this approach does not substantially change disease progression or reduce mortality ${ }^{(15)}$.
More importantly, these treatments do not improve the many and varied systemic manifestations of COPD. The only oral medication for COPD is roflumilast, which is limited to severe disease characterized by recurrent acute exacerbations of COPD ${ }^{(16,17)}$.

This study is a clinical trial to assess the efficacy and safety of statin therapy in 2 different doses (high vs. low dose vs. placebo) for COPD patients with evidence of inflammatory markers as high sensitivity CRP (HsCRP) in term of severity, hospitalization and mortality.

\section{Methods}

Ninety patients from both genders were included in the study, whom age from 40 years and above. They were treated at the outpatient private clinic in Babylon government, Iraq, during the period from September 2012 to April 2016.

Inclusion criteria considered any patients with diagnosis of COPD by consistent history of smoking, clinical manifestation with spirometric criteria and high resolution computerized tomography (HRCT) findings who don't have any other diseases like ischemic heart disease, diabetes mellitus, hypertension or dyslipidemia neither before nor at time of diagnosis. For all enrolled patient, there is evidence of inflammation detected by positive HsCRP. All patients were in stable state maintained using inhaled budesonide /formeterol (160/4.5) twice daily and/or long acting anticholinergic and/or phyllocontine (225 mg) at night.

Those who are excluded from the trial included any patient refused the participation in the study or those with no obvious diagnosis of COPD or patients presenting during exacerbation episodes and patients not under regular treatment.

The 90 patients were divided equally and randomly into 3 groups:

Group 1: Thirty patients receive atorvastatin 40 mg at night

\section{4}


Group 2: Thirty patients receive atorvastatin 10 mg at night

Group 3: Thirty patients receive placebo treatment in addition to their baseline treatment for all 3 groups.

All patients are assessed at zero time for severity using chronic obstructive airway disease assessment test (CAT) score (clinical questions used to assess the control briefly by the patients word), spirometry in addition to their initial liver function tests, creatinine phosphokinase and HsCRP. A second assessment performed at 6 months' time for all the above initial evaluation as well as inquiring for COPD-induced hospitalization, exacerbations attacks and over-all mortality, in addition to adverse effect like myopathy or hepatitis picture necessitate medical seek. Primary end-points were reduction in HsCRP (inflammatory markers), FEV1 changes (physiological markers) and CAT score changes (clinical markers for diseases control). Secondary end-points were frequency of hospitalization, exacerbation and over-all mortality. Safety issues were also assessed like GIT effect, CNS effect as dizziness and amnesia, liver effect and myopathy.

Statistical analysis was carried out using SPSS version 17. Categorical variables were presented as frequencies and percentages. Continuous variables were presented as (Mean \pm SD). Paired t-test was used to compare means between paired numerical readings when difference between readings was normally distributed. Wilcoxon Signed Ranks Test was used to compare means between paired numerical readings when difference between readings was not normally distributed. A $p$-value of $\leq 0.05$ was considered as significant.

\section{Results}

\section{Patients' demography}

As shown in table 1, the majority of patients were males and old age as the risk factor is smoking, which have a stronger effect in male and in elderly.

\section{Table 1. The Distribution of patients with} COPD according to age gender

\begin{tabular}{ccc}
\hline Age (years) & $\begin{array}{c}\text { Mean } \\
(64.52 \pm 7.14)\end{array}$ & $\begin{array}{c}\text { Range } \\
(45-78)\end{array}$ \\
\hline Gender & No. & $\%$ \\
\hline Male & 51 & 56.7 \\
Female & 39 & 43.3 \\
\hline Total & 90 & 100.0 \\
\hline
\end{tabular}

Regarding frequency of hospital admissions in the 6 months of study; the majority of the patients does not need hospitalization as most of them could be treated as an outpatient as shown in (Figure 1).

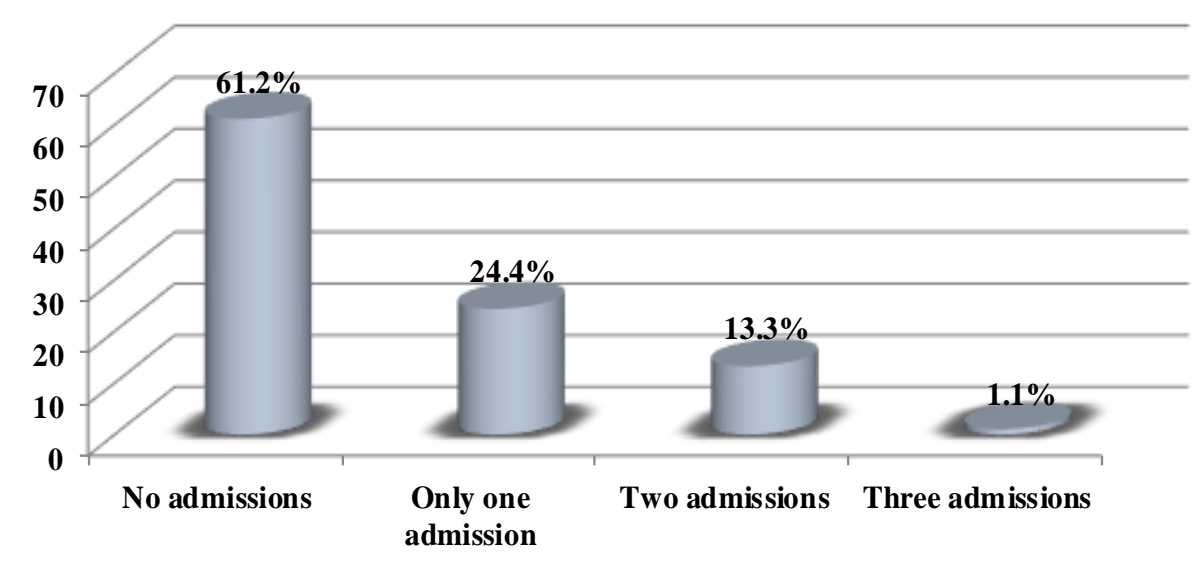

Figure 1. Distribution of patients according to frequency of hospital admissions 
The distribution of patients with COPD according to frequency of exacerbations in the 6 months of the study is shown in (Figure 2) where the majority showed 1-2 attacks of exacerbation in a relatively short period, which represent the heavy burden of this disease on the health budget.

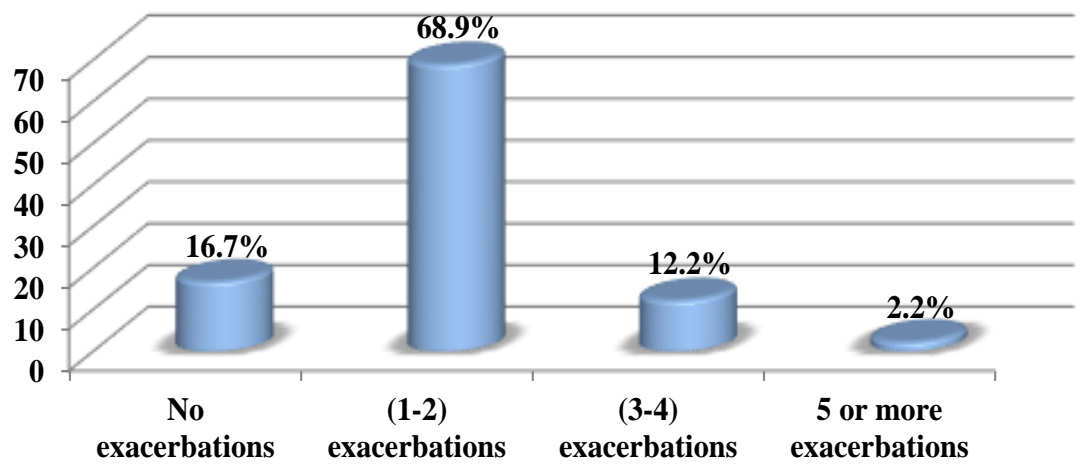

Figure 2. Distribution of patients according to frequency of exacerbations.

The distribution of patients with COPD according to side effects developed in the study duration: Both groups showed side effects, which mean that these effects may be not related to the drug treatment alone but also to the disease itself as shown in (Table 2).

Table 2. Distribution of patients according to side effects

\begin{tabular}{ccc}
\hline Clinical side effects & Number & $\%$ \\
\hline Nervous system & 28 & \\
Yes & 62 & 31.1 \\
No & 90 & 68.9 \\
Total & & 100 \\
\hline Liver abnormalities & 3 & \\
Yes & 87 & 3.3 \\
No & 90 & 96.7 \\
Total & & 100 \\
\hline Gastrointestinal system & 44 & \\
No & 46 & 48.9 \\
Total & 90 & 51.1 \\
Myopathy & & 100 \\
Yes & 10 & 11.1 \\
No & 80 & 88.9 \\
Total & 90 & 100 \\
\hline
\end{tabular}


Figure 3 shows the distribution of patients with COPD according to death in the study duration where death occurs in about (10\%) of patients.

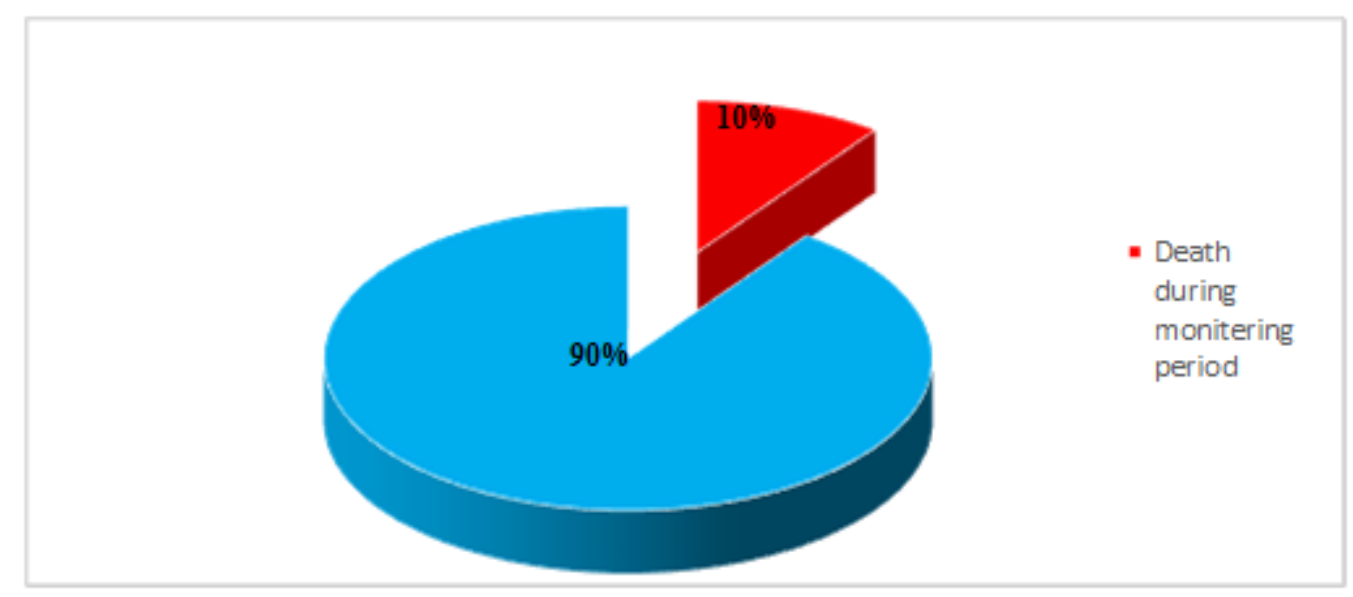

Figure 3. Distribution of patients according to death occurrence

The Study Groups and Study Variables analysis There were no significant differences between means of age \& gender in the three study groups as shown in (Tables 3 and Table 4) which indicate matching of the three groups.

Table 3. The mean differences of age by study groups

\begin{tabular}{ccccc}
\hline Gender & $\begin{array}{c}\text { Group 1 } \\
\text { No. (\%) }\end{array}$ & $\begin{array}{c}\text { Group 2 } \\
\text { No. (\%) }\end{array}$ & $\begin{array}{c}\text { Group 3 } \\
\text { No. (\%) }\end{array}$ & P-value \\
\hline Male & $17(56.7)$ & $14(46.7)$ & $20(66.7)$ & \\
Female & $13(43.3)$ & $16(53.3)$ & $10(33.3)$ & 0.295 \\
Total & $30(100)$ & $30(100)$ & $30(100)$ & \\
\hline
\end{tabular}

${ }^{*} p$ value $\leq 0.05$ was significant

$* * p$ value $\leq 0.01$ was highly significant

Table 4. The Distribution of patients with COPD according to age with each study groups

\begin{tabular}{cccc}
\hline Study groups & No. & $\begin{array}{c}\text { Age } \\
\text { Mean } \pm \text { SD }\end{array}$ & P value \\
\hline Group 1 & 30 & $65.06 \pm 6.52$ & \\
Group 2 & 30 & $65.23 \pm 5.56$ & 0.502 \\
Group 3 & 30 & $63.26 \pm 8.97$ & \\
\hline
\end{tabular}

Table 5 shows mean differences of HsCRP, CATscore and FEV1 after treatment by study groups, there were significant differences between means of HsCRP and FEV1 by study groups, while there were no significant differences between means of CAT- score by study groups. 
Baay, The Role of atorvastatin in the treatment of COPD ....

Table 5. Mean differences of CRP, CAT-score and FEV1 after treatment by study groups

\begin{tabular}{ccccc}
\hline Variable & Study groups & No. & Mean \pm SD & P-value \\
\hline \multirow{3}{*}{ CRP } & Group 1 & 28 & $2.98 \pm 1.05$ & \\
& Group 2 & 28 & $3.32 \pm 1.02$ & $<0.001^{*}$ \\
& Group 3 & 25 & $4.57 \pm 0.67$ & \\
CAT-score & Group 1 & 28 & $18.92 \pm 5.44$ & \\
& Group 2 & 28 & $17.60 \pm 5.43$ & 0.53 \\
& Group 3 & 25 & $18.96 \pm 4.05$ & \\
\hline \multirow{3}{*}{ FEV1 } & Group 1 & 28 & $47.96 \pm 7.63$ & \\
& Group 2 & 28 & $47.57 \pm 8.46$ & $0.033^{*}$ \\
& Group 3 & 25 & $42.76 \pm 7.25$ & \\
\hline
\end{tabular}

Note: 9 patients from all groups died during follow up, *p value $\leq 0.05$ was significant

The mean differences of HsCRP level, CAT- statin using (40 mg/day) is illustrated in table 6; score and FEV1 before and after high dose of were statistically significant.

Table 6: The mean differences of HsCRP, CAT-Score and FEV1 before and after high dose of statin

\begin{tabular}{|c|c|c|c|c|}
\hline Variable & Categories & No. & Mean & $P$ value \\
\hline \multirow{2}{*}{ HsCRP } & Before treatment & 28 & $4.37 \pm 0.94$ & \multirow{2}{*}{$<0.001^{*}$} \\
\hline & After treatment & 28 & $2.98 \pm 1.05$ & \\
\hline \multirow{2}{*}{ CAT-score } & Before treatment & 28 & $23.82 \pm 5.38$ & \multirow{2}{*}{$<0.001^{*}$} \\
\hline & After treatment & 28 & $18.92 \pm 5.44$ & \\
\hline \multirow{2}{*}{ FEV1 } & Before treatment & 28 & $38.28 \pm 6.96$ & \multirow{2}{*}{$<0.001^{*}$} \\
\hline & After treatment & 28 & $47.96 \pm 7.63$ & \\
\hline
\end{tabular}

Note: Two patients from this group died during follow up, ${ }^{*} p$ value $\leq 0.05$ was significant

The mean differences of CRP level, CAT-score and FEV 1 before and after high dose of statin using $(10 \mathrm{mg} /$ day) is shown in table 7 ; were also statistically significant.

There was a statistically significant association between use of statin, frequency of hospital admissions and frequency of exacerbations among patients with chronic obstructive airway diseases as shown in table 8.
Regarding mortality, there was no significant association between use of statin and patient's mortality as shown in table 9.

There was significant association between use of statin and gastrointestinal upset and myopathy; while there was no significant association between use of statin and other system effects as shown in table 10. 
Table 7. The mean differences of HsCRP, CAT-Score and FEV1 before and after low dose of statin

\begin{tabular}{ccccc}
\hline Variable & Categories & No. & Mean & P value \\
\hline \multirow{2}{*}{ HsCRP } & Before treatment & 28 & $4.53 \pm 0.84$ & \multirow{2}{*}{ ( } \\
& After treatment & 28 & $3.32 \pm 1.02$ & $<001^{*}$ \\
\hline \multirow{2}{*}{ CAT-score } & Before treatment & 28 & $22.46 \pm 5.29$ & $<0.001^{*}$ \\
& After treatment & 28 & $17.60 \pm 5.43$ & \\
\hline \multirow{2}{*}{ FEV1 } & Before treatment & 28 & $39.35 \pm 5.95$ & $<0.001^{*}$ \\
& After treatment & 28 & $47.57 \pm 8.46$ & \\
\hline
\end{tabular}

Note: Two patients from this group died during follow up, ${ }^{*} p$ value $\leq 0.05$ was significant

Table 8. Association between patients' groups and frequency of exacerbation or hospital admissions

\begin{tabular}{cccccc}
\hline \multicolumn{2}{c}{ Study variables } & $\begin{array}{c}\text { High dose } \\
\text { No. (\%) }\end{array}$ & $\begin{array}{c}\text { Study Groups } \\
\text { Low dose } \\
\text { No. (\%) }\end{array}$ & $\begin{array}{c}\text { Placebo } \\
\text { No. (\%) }\end{array}$ & P value \\
\hline Number of & No & $23(76.7)$ & $19(63.3)$ & $13(43.3)$ & $0.029^{*}$ \\
admission & One or more & $7(23.3)$ & $11(36.7)$ & $17(56.7)$ & \\
\hline Number of & No & $6(20.0)$ & $7(23.3)$ & $2(6.7)$ & \\
exacerbations & 1 or 2 & $24(80.0)$ & $21(70.0)$ & $17(56.6)$ & $<0.001^{*}$ \\
\hline
\end{tabular}

*p value $\leq 0.05$ was significant

Table 9. Association between study groups and mortality

\begin{tabular}{ccccc}
\hline & $\begin{array}{c}\text { High dose } \\
\text { No. (\%) }\end{array}$ & $\begin{array}{c}\text { Low dose } \\
\text { No. (\%) }\end{array}$ & $\begin{array}{c}\text { Placebo } \\
\text { No. (\%) }\end{array}$ & P-value \\
\hline Dead during follow up & $2(6.7)$ & $2(6.7)$ & $5(16.7)$ & 0.494 \\
\hline Still alive after follow up period & $28(93.3)$ & $28(93.3)$ & $25(83.3)$ & \\
\hline
\end{tabular}

$* p$ value $\leq 0.05$ was significant

\section{Discussion}

The majority of patients (61.2\%) does not need hospitalization despite that $68.9 \%$ show single exacerbation, which means that much patients with mild COPD exacerbation can be treatment as outpatients, this finding is consistent with most of the clinical practice data ${ }^{(18)}$. Both the overall side effects seen in the study groups (statin or the placebo groups) are more in the GI upset and muscular effect, this was expected finding as the both can be induced by the drugs or the disease itself ${ }^{(19)}$. The overall mortality is $10 \%$ over 6 months, 5 patients of them in the placebo arm but the difference is not statistically significant, this finding is higher than Kirchmayer et al, which may be due to small sample size. The effect on all-cause mortality is a gray area because it is possible that there are potential beneficial effects of statins on cardiovascular comorbidities as it is known that smoking is a causative factor in the majority of patients with COPD and in the 
development of coronary artery disease. COPD patients ${ }^{(20)}$. Cardiovascular comorbidities are common in

Table 10. Association between study groups and side effects

\begin{tabular}{ccccc}
\hline Clinical manifestations & $\begin{array}{c}\text { High dose } \\
\text { No. (\%) }\end{array}$ & $\begin{array}{c}\text { Study Groups } \\
\text { Low dose } \\
\text { No. (\%) }\end{array}$ & $\begin{array}{c}\text { Placebo } \\
\text { No. (\%) }\end{array}$ & P value \\
\hline $\begin{array}{c}\text { GIT upset } \\
\text { Present }\end{array}$ & $22(73.3)$ & $11(36.7)$ & $11(36.7)$ & \\
Absent & $8(26.7)$ & $19(63.3)$ & $19(63.3)$ & $0.005^{*}$ \\
\hline CNS & $11(36.7)$ & $10(33.3)$ & $7(23.3)$ & \\
Present & $19(63.3)$ & $20(66.7)$ & $23(76.7)$ & 0.510 \\
Absent & $3(10.0)$ & $0(0.0)$ & $0(0.0)$ & \\
Liver effects & $27(90.0)$ & $30(100.0)$ & $30(100.0)$ & 0.104 \\
Present & $7(23.3)$ & $3(10.0)$ & $0(0.0)$ & \\
Absent & $23(76.7)$ & $27(90.0)$ & $30(100.0)$ & $0.015^{*}$ \\
\hline Myopathy & & & \\
Present & & & \\
Absent & & & & \\
\hline
\end{tabular}

$* p$ value $\leq 0.05$ was significant

The finding from the current study that statins not reduced mortality in patients with COPD were inconsistent with most of the included studies ${ }^{(21,22)}$. However, a large multi-centre randomized clinical trial showed that statins had no effect on COPD exacerbations, which was consistent with this finding ${ }^{(23)}$. Several reasons might be accountable for this; only moderate-to-severe COPD patients were included in these studies and it is unclear whether statins were beneficial for patients with less impairment. In addition, the mean followed-up time was around 2 years, which might be a significantly different compared to the short-term effect in this study. Although the statin show a significant improvement in the both treated groups regarding the HsCRP, CAT score and FEV1 after 6 months of treatment, this improvement fail to show significant effect on CAT score when compared to placebo group i.e. the statin treatment not show symptomatic improvement measured by CAT score over placebo treatment. These findings consistent with some studies and inconsistent with others and that because it is depend on the study criteria and design as seen in Carlson et al study ${ }^{(24)}$. The statin treatment showed significant improvement of hospitalization, number of exacerbations but not mortality, again this finding is not proved yet ${ }^{(23,26)}$. The useful effect of statin was shown both in high and low dose in all primary endpoints but the side effects were higher in high dose arm as expected as the statin side effects are dose dependent ${ }^{(27)}$.

In conclusion; atorvastatin use in COPD may have some beneficial effects on the disease profile mainly on the inflammatory aspects in addition to possible another useful effect on lung functions decline, frequency of exacerbations, hospitalization and even symptomatology of the patients. However, there is no clear benefits of statin in all-cause mortality outcome. The gastrointestinal and muscular adverse effects were significantly higher in the treatment groups patients. 
It is recommended now to study the statin use in COPD in larger study with a longer duration and use other family drugs members and other doses to see whether it is group or drug related effects as well as using other inflammatory markers like interleukins (IL6) or tumor necrosis factor (TNF) to confirm their effect of the treatment in COPD.

\section{Acknowledgments}

Great thanks to my teachers, collages and statistician whom help me in this work and mostly to my patients whom participate in this work.

\section{Conflict of interest}

Drugs supplier and the payment for the drugs cost.

\section{Funding}

The study was funded by the own researcher budget.

\section{References}

1. Janda S, Park K, Fitzgerald JM, et al. Statins in COPD. Chest. 2009; 136: 734-43.

2. Young RP, Hopkins RJ, Eaton TE. Potential benefits of statins on morbidity and mortality in COPD: a review of the evidence. Postgrad Med J. 2009; 85: 414-21.

3. Dobler CC, Wong KK, Marks GB. Association between statins and COPD: a systematic review. BMC Pulm Med. 2009; 9: 32. DOI: 10.1186/1471-2466-9-32

4. Young RP, Hopkins RJ, Eaton TE. Pharmacological actions of statins: potential utility in COPD. Eur Respir Rev. 2009; 18: 222-32.

5. Barnes PJ, Celli BR. Systemic manifestations and comorbidities in COPD. Eur Respir J. 2009; 33: 1165-85.

6. Melbye $H$, Halvorsen DS, Hartz I, et al. Bronchial airflow limitation, smoking, body mass index, and statin use are strongly associated with the C-reactive protein level in the elderly. Resp Med. 2007; 101: 2541-9.

7. Agusti A, Edwards LD, Rennard SI, et al. Persistent systemic inflammation is associated with poor clinical outcomes in COPD: a novel phenotype. PLoS One. 2012; 7(5): e37483. doi: 10.1371/journal.pone.0037483

8. Sinden NJ, Stockley RA. Systemic inflammation and co-morbidity in COPD: a result of 'overspill' of inflammatory mediators from the lungs? Review of the evidence. Thorax. 2010; 65: 930-6.
9. Walter RE, Wilk JB, Larsen MG, et al. Systemic inflammation and COPD: the Framingham Heart Study. Chest. 2008; 133: 19-25.

10. Lee T-M, Lin M-S, Chang N-C. Usefulness of C-reactive protein and interleukin- 6 as predictors of outcomes in patients with chronic obstructive pulmonary disease receiving pravastatin. Am J Cardiol. 2008; 101: 530-5.

11. Cazzola M, Page CP, Calzetta $L$, et al. Emerging antiinflammatory strategies for COPD. Eur Respir J. 2012; 40: 724-41.

12. Mannino DM, Valvi D, Mullerova H. Fibrinogen, COPD and mortality in a nationally representative U.S. cohort. COPD. 2012; 9: 359-66.

13. Hurst JR, Hagan G, Wedzicha JA. Mechanism of statin-associated mortality reduction in COPD. Chest. 2007; 132: 1409.

14. Ahmad T, Mabalirajan U, Sharma A, et al. Simvastatin improves epithelial dysfunction and airway hyperresponsiveness. From asymmetric dimethylarginine to asthma. Am J Respir Cell Mol Biol. 2001; 44: 531-9.

15. Rasmussen F, Mikkelsen D, Hancox RJ, et al. Highsensitive C-reactive protein is associated with reduced lung function in adults. Eur Respir J. 2009; 33: 382-8.

16. Hoiseth AD, Neukamm A, Karlsson BD, et al. Elevated high-sensitivity cardiac troponin $T$ is associated with increased mortality after acute exacerbation of chronic obstructive pulmonary disease. Thorax. 2011; 66: 775-81.

17. Chang SS, Vaz Fragoso CA, Van Ness $\mathrm{PH}$, et al. Association between combined interleukin- 6 and Creactive protein levels and pulmonary function in older women; results from the Women's Health and Aging Studies I and II. J. Am Geriatr Soc. 2011; 59: 113-9.

18. Stoller JK. Management of exacerbations of chronic obstructive pulmonary disease. UpToDate. literature review current through: Apr 2016. This topic last updated: Mar 17, 2016.

19. Thompson PD, Panza G; Zaleski A, et al. Statinassociated side effects. J Am Coll Cardiol. 2016; 67(20): 2395-410.

20. Kirchmayer $U$, Cascini S, Agabiti N, et al. One-year mortality associated with COPD treatment: a comparison of tiotropium and long-acting beta2agonists in three Italian regions: results from the OUTPUL study. Pharmacoepidemiol Drug Safety. 2016; 25: 578-89.

21. Sheng $X$, Murphy MJ, MacDonald TM, et al. Effect of statins on total cholesterol concentrations, cardiovascular morbidity, and all-cause mortality in chronic obstructive pulmonary disease: a populationbased cohort study. Clin Ther. 2012; 34: 374-84. 
Baay, The Role of atorvastatin in the treatment of COPD ....

22. Lawes CM, Thornley $S$, Young $R$, et al. Statin use in COPD patients is associated with a reduction in mortality: a national cohort study. Prim Care Respir J. 2012; 21: 35-40.

23. Criner GJ, Connett JE, Aaron SD, et al. Simvastatin for the prevention of exacerbations in moderate-tosevere COPD. New Engl J Med. 2014; 370: 2201-10.

24. Carlson AA, Smith EA, Reid DJ. The stats are in: an update on statin use in COPD. Int J Chronic Obstruct Pulmonary Dis. 2015; 10: 2277-84.

25. Cao $C, W u Y, X u Z$, et al. The effect of statins on chronic obstructive pulmonary disease exacerbation and mortality: a systematic review and meta-analysis of observational research. Sci Rep. 2015; 5: 16461. doi: $10.1038 /$ srep16461.
26. Horita N, Miyazawa N, Kojima R, et al. Statins reduce all-cause mortality in chronic obstructive pulmonary disease: a systematic review and meta-analysis of observational studies. Respir Res. 2014; 15: 80. doi: 10.1186/1465-9921-15-80.

27. Ambrocio G, Roque IA, Jorge II MPPC. Improving patient therapies in COPD P253 Meta - Analysis on statins in chronic obstructive pulmonary disease. Thorax. 2014; 69: A188. doi:10.1136/thoraxjnl-2014206260.381.

E-mail: ali_salh64@yahoo.com Received 22 ${ }^{\text {nd }}$ Jun. 2016: Accepted $19^{\text {th }}$ Nov. 2016 